\title{
Biocoating of Seeds with Plant Growth-Promoting Rhizobacteria to Improve Plant Establishment
}

\author{
B. Schippers ${ }^{1}$, R. J. Scheffer ${ }^{2}$, B. J. J. Lugtenberg ${ }^{3}$ and P. J. Weisbeek ${ }^{4}$ \\ 'Department of Plant Ecology and Evolutionary Biology, University of Utrecht, PO Box 80084, \\ 3508 TB Utrecht, Netherlands \\ ${ }^{2} S$ \& G Seeds B.V., Westeinde 62, 1600 AA Enkhuizen, Netherlands \\ ${ }^{3}$ Institute of Molecular Plant Science, Clusius Laboratory, University of Leiden, Wassenaarseweg \\ 64, 2333 AL Lieden, Netherlands \\ ${ }^{4}$ Department of Molecular Cell Biology, University of Utrecht, Padualaan 8, 3584 CH Utrecht, \\ Netherlands
}

Plant growth-promoting rhizobacteria (PGPRs) have the potential to contribute significantly to the development of sustainable

agricultural systems. Our understanding at the molecular level of the interactions between these microorganisms, the plant and the environment is growing rapidly, facilitating the development of microbial products. However, their development is hampered by the legislative restrictions on their use and consequently high costs. This is especially true because biocontrol agents are often specific to crops, pathogens and soil types. Nevertheless, promising new products for the improvement of plant establishment and plant growth, such as 'BioCoat' for radish seeds, have entered the market.

Outlook on Agriculture Vol. 24, No. 3. 179-185 (1995)
Bob Schippers is Emeritus Professor of plant pathology at Utrecht University. He was previously director of the Willie Commelin Scholten Phytopathological Laboratory at Baarn, in the Netherlands, and is now editor-in-chief of the European Journal of Plant Pathology. Ben Lugtenberg is professor of plant microbiology at the University of Leiden and Peter Weisbeek is professor of genetics at the University of Utrecht. Rudy Scheffer is research leader at $S$ $\mathcal{E} G$ Seeds B.V., Enkhuizen. The authors have cooperated for more than 10 years on fundamental and applied aspects of plant growth-promoting Pseudomonas bacteria, isolated and selected at Baarn. Their cooperation was supported by the Netherlands Technology Foundation (STW) and resulted in several EU-financed projects, such as 'Biological inoculants for seed/plant establishment' (1990-94) within the ECLAIR programme, in association with research institutes and industries in Ireland, France and Italy. It also resulted in the commercial product 'BioCoat' for radish seed.
A major strategy to counteract the rapid decline in environmental quality is the development of a sustainable agriculture. This demands continuous advances in biological productivity, achieved in an ecologically sustainable manner (Swaminathan, 1991). Challenging possibilities are offered by the combination of a gradual reduction of the use of pesticides and fertilizers on one hand and a greater use of the biological and genetical potential of plant and microbial species on the other hand.

Plant growth-promoting rhizobacteria (PGPRs) are of particular interest for the improvement of seedling establishment and plant growth they produce and for the biological control of plant diseases
(Schippers, 1992; Cook, 1993). PGPRs have been isolated from plant parts collected from field soil. They aggressively colonize roots and have been selected for their ability to improve plant growth either through direct effects on the plant (Lugtenberg et al., 1991) or by suppressing soilborne pathogens and other deleterious rhizosphere microorganisms (Schippers 
et al., 1987; Thomashow and Weller, 1995).

Except for a few important applications, such as nitrogen fertilization of legumes by application of rhizobia and control of crown gall with Agrobacterium radicicola strain $\mathrm{K}-84$, the largescale application of PGPRs in agricultural practice has been hampered by the inconsistency of the results. This can be partly ascribed to a limited knowledge of the ecology of PGPRs and of the mechanisms of their plant growth promotion. But especially over the last five years, molecular biological and genetical approaches have resulted in a rapidly increasing understanding of plant growth promotion by these bacteria. This opens up the possibility of selecting for better strains and of improving the performance of PGPRs by altering their genetic regulation. It also allows for evaluation of the potentials and limitations of their use in agriculture.

The development of commercial applications of PGPRs has also been influenced by the requirements for their registration as a 'microbial pesticide', the costs of which are a formidable barrier. This paper focuses on fluorescent Pseudomonas spp., the best characterized PGPR used in the biocoating of seeds, and on the improvement of plant establishment as the most successful application so far.

\section{Mechanisms of plant growth promotion}

The analysis of the mechanisms underlying plant growth promotion and disease suppression by PGPRs originates in the unravelling of the microbial characteristics of some localized, naturally disease-suppressive soils and of plant growth promotion by root-colonizing bacteria (Schippers, 1992; Cook, 1993; Voisard et al., 1994; Alabouvette et al., 1995). Naturally disease-suppressive soils prohibit the development of particular soilborne diseases, despite the ubiquitousness of the causal pathogen. The suppression is of soil-microbial origin. The best studied of these special soils are in the State of Washington, in Switzerland and in France. The Washington soils effectively suppress takeall in wheat caused by the fungus Gaeumannomyces graminis, while in Switzerland soils were found that

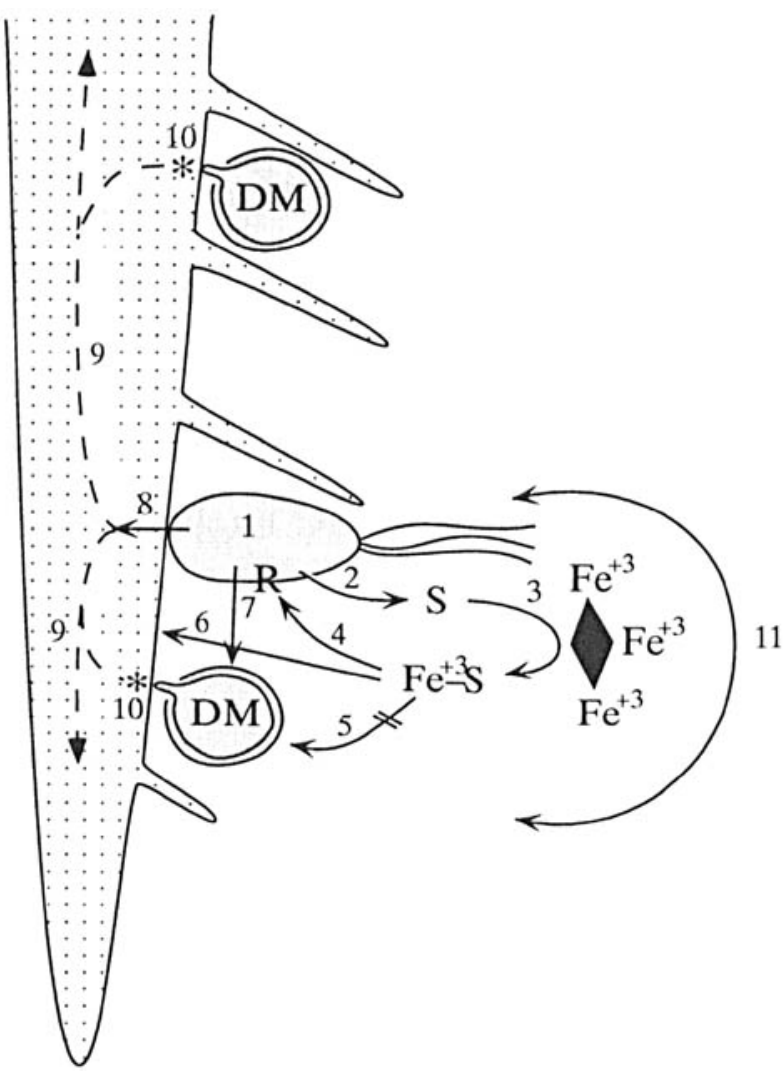

Figure 1 Diagram of interactions between a PGPR (1), a deleterious microorganism (DM), the plant root and the soil environment. In reality, the PGPR is present as a microcolony on the root surface. 1. Colonization of the root tip by PGPRs. 2. Production and release of siderophore(s) (S) at low iron availability in soil. 3. Complexation of $\mathrm{Fe}^{3+}$ by $S$ from a soil particle. 4. Recognition of $\mathrm{Fe}^{3+}-\mathrm{S}$ by receptor (R) and uptake into PGPR cell. 5. Fe $e^{3+}-\mathrm{S}$ cannot be used by DM. 6. Utilization of $\mathrm{Fe}^{3+}$ from Fe $\mathrm{e}^{3+}-\mathrm{S}$ by plant. 7. Antibiotic(s) produced by PGPR suppressing DM. 8. Induction of systemic resistance in plant by a trigger (e.g. cell wall LPS). 9. Signal transport. 10. Defence reactions where the DM attacks $\left(^{*}\right) .11$. Soil environmental factors that affect interactions between PGPR,DM and plant.

suppress black root rot of tobacco caused by the fungus Thielaviopsis basicola, and in France particular soils are known to be suppressive to fusarium wilt disease caused by the fungus Fusarium oxysporum (Schippers, 1992). The suppressiveness of the Washington and Swiss soils is ascribed to PGPR strains of fluorescent Pseudomonas spp., and of the French to a co-operation between fluorescent Pseudomonas strains and non-pathogenic strains of Fusarium oxysporum (Alabouvette et al., 1995).

The major mechanisms for disease suppression by PGPR are based on competition for nutrients, induction of plant resistance and antibiosis. Optimal functioning of PGPR strains is highly influenced by environmental factors including soil characteristics, plant species and rhizosphere microflora (Figure 1).

\section{Competition for nutrients}

One of the earliest mechanisms of plant growth promotion studied is the competition for iron between plant growth-promoting Pseudomonas bacteria and deleterious microorganisms in the rhizosphere. It is mediated by iron-sequestering metabolites called siderophores (Bakker et al., 1993; Figure 1). In this respect the PGPR strain Pseudomonas putida WCS358 is significant because it produces a siderophore that cannot be used by the deleterious microorganism, only by a limited number of other rhizosphere pseudomonads. At the same time it is equipped with a variety of siderophore receptors in its cell membrane that most other pseudomonads do not have (Koster, 1994). These receptors enable this PGPR to sequester iron also by utilizing the specific siderophores of many other pseudomonads. This 
contributes to its competitive power in the rhizosphere (Raaijmakers $\mathrm{et}$ al., 1995).

The potential contribution of siderophores to disease suppression is limited to rhizosphere conditions that favour their production and release: the availability of ferric iron in the environment must be low. Siderophore production of particular Pseudomonas strains such as P. putida WCS358 has been demonstrated to be involved in the promotion of plant growth and in the suppression of deleterious bacteria and fungi. Tn5 mutants that had lost the ability to produce the siderophore suppressed disease or improved plant growth to a lesser extent or not at all, when compared to their parent strain (Bakker et al., 1993).

Siderophore-mediated competition for iron may also reinforce the suppression of soilborne pathogens by other microorganisms. For example, P. putida strain WCS358 was demonstrated to improve the suppression of the fusarium wilt disease of carnation by a non-pathogenic strain of the fusarium wilt pathogen. Because the pathogen is less efficient at iron uptake than the non-pathogen it is more seriously weakened by the competition from $P$. putida, and it then also suffers in the competition for organic carbon (Alabouvette et al., 1995).

Nutrients released by germinating seeds and root tips stimulate the germination and growth of many deleterious micro-organisms prior to infection. If these nutrients are metabolized by PGPRs instead of by deleterious micro-organisms, this may significantly contribute to seedling establishment. Emergence of seedlings in Pythium-infested soil was enhanced when seeds had been treated with a selected Pseudomonas strain that reduced both the concentration of organic volatiles released and the saprophytic growth of Pythium (Paulitz, 1991).

The rate at which a PGPR strain attains its required population density and metabolic activity on germinating seeds and seedlings has been shown to be critical in successfully curtailing the activity of deleterious microorganisms.

\section{Induction of systemic resistance}

Induction of systemic resistance in plants was only recently shown to be involved in the suppression of several fungal, viral and bacterial diseases by different PGPR Pseudomonas strains. Of two strains, the induction of such a systemic resistance was shown to be triggered by the $\mathrm{O}$-antigen side chain of the lipopolysaccharides which form a major component of the outer layer of the Pseudomonas cell wall. In this way, resistance against fusarium wilt in carnation and radish was induced by the $P$. fluorescens strains WCS417 and WCS374, respectively (Leeman et al., 1995b; Van Peer et al., 1991).

Low availability of ferric iron in the environment appears significantly to enhance the induction of systemic resistance in radish against fusarium wilt disease by strain WCS374. This seems to be due to its increased production of salicylic acid and pseudobactin siderophores, both of which have been shown to have the potential to trigger the induction of systemic resistance in radish (Leeman et al., 1995a).

The potential to induce systemic resistance is probably widely distrib-

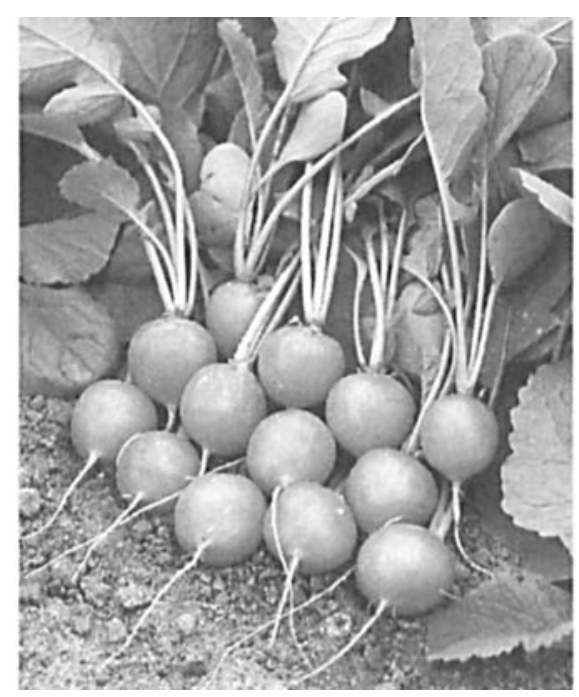

Radishes of cv. Gudar (S \& G Seeds).

uted among fluorescent pseudomonads and other root-inhabiting saprophytic microorganisms. The possibility also cannot be ruled out that they play a major role in natural disease-suppressive soils (Schippers, 1992). Studies on the genetic basis of PGPR-induced systemic resistance in Arabidopsis thaliana are in progress. They will open up new ways of exploring this phenomenon and using it to further improve plant growth by PGPRs.

The already well described systemic acquired resistance (SAR) which can be activated by necrosis-inducing pathogens and certain abiotic agents is associated with the activation of pathogenesis-related (PR) proteins in the plant (Hammerschmidt and Kuć, 1995). PR proteins could not be demonstrated in radish and Arabidopsis thaliana when induced systemic resistance was activated by $P$. fluorescens WCS417 (Hoffland et al., 1995; C. Pietersen, personal communication).

Although crop specificity occurs, some fluorescent Pseudomonas strains have the potential to induce systemic resistance in a variety of cultivars widely differing in susceptibility to disease, or in more than one crop against several plant pathogens. Induced systemic resistance in plants is attractive from an environmental point of view, as it does not inhibit or kill the pathogen directly by a toxic metabolite, but restricts its penetration into the plant by optimizing the plant's defence system.

\section{Antibiosis}

The production of antibiotic compounds is a common feature among rhizosphere-inhabiting fluorescent pseudomonads. Their significance in the suppression of a variety of soilborne plant pathogens by a selected number of antibiotic-producing PGPR strains has been studied in detail (Thomashow and Weller, 1995).

Suppression of take-all in wheat by strains $P$. fluorescens 2-79 and $P$. aureofaciens $30-80$, selected from disease-suppressive soils in the northwest of the USA, is primarily determined by their production of phenazine antibiotics. In some take-allsuppressive soils, however, a relatively high percentage of fluorescent pseudomonads produce phloroglucinol antibiotics. The effective suppression of take-all by strain P. fluorescens Q2-87 selected from such soils is primarily based on this antibiotic.

The phloroglucinol antibiotic is also an important determinant in the suppression of take-all by $P$. fluorescens strain $\mathrm{CHAO}$ isolated from soils suppressive to black root rot of tobacco in Switzerland. This strain, however, produces many other bioactive compounds among which are pyoluteorin 
and HCN (Voisard et al., 1994). Both acetylphloroglucinols and $\mathrm{HCN}$ contribute to the suppression of black root rot in tobacco. In particular, 2,4diacetylphloroglucinol has been associated with biocontrol activity of fluorescent pseudomonads from all over the world. In Pseudomonas sp. strain F113 selected from Irish soils, this compound is the major metabolite involved in the suppression of the pathogenic soil fungus Pythium ultimum in sugarbeet (see Thomashow and Weller, 1995).

Other antibiotics that have been shown to be responsible for, or involved in, the improved survival and growth of seedlings induced by fluorescent $P$ seudomonas strains are pyoluteorin, pyrrolnitrin and oomycin. Pyoluteorin, for example, is highly inhibitory to Pythium ultimum, but not to other seedling pathogens such as the fungi Rhizoctonia solani, Verticillium dahliae, Fusarium spp. and Thielaviopsis basicola. Pyrrolnitrin can be produced by a wide variety of Pseudomonas strains, many of which were shown to have biocontrol potential. Pyrrolnitrin produced by $P$. fluorescens Pf- 5 was shown to be responsible for increased emergence and survival of cotton seedlings in $R$. solani-infested soil and to be active against the pathogenic soil fungi Alternaria sp., T. basicola and $V$. dahliae, but not against $P$. ultimum (see Thomashow and Weller, 1995).

There is some concern about the application of microorganisms whose disease-suppressive potential is based on the release of antibiotics or other biocidal metabolites. Some antibiotics, such as 2,4-diacetylphloroglucinol and pyoluteorin, have herbicidal characteristics at high concentrations. This observation has caused some concern about the application of microorganisms which release antibiotics or other biocidal metabolites. However, the PGPR strains used to develop biocoated seeds and to suppress disease in field soil generally produce the antibiotic metabolites in the rhizosphere in quantities far below the phytotoxic level. Phytotoxicity has however been shown for genetically modified strains that overproduce an antibiotic metabolite, for example a modified strain of $\mathrm{CHAO}$ overproducing pyoluteorin and 2,4-diacetylphloroglucinol and becoming toxic for cress and sweetcorn. It should be noted that overproduction does not necessarily improve disease suppressiveness (Thomashow and Weller, 1995).

\section{Root competence}

Many of the selected PGPR

Pseudomonas strains show significant plant growth promotion and/or disease suppression in the field, when applied as a seed coating (Thomashow and Weller, 1995). In most cases, however, results have been variable or not comparable to those achieved with agrochemicals. It has to be emphasized, however, that for many soilborne diseases pesticides are not available, are too expensive, or have been banned.

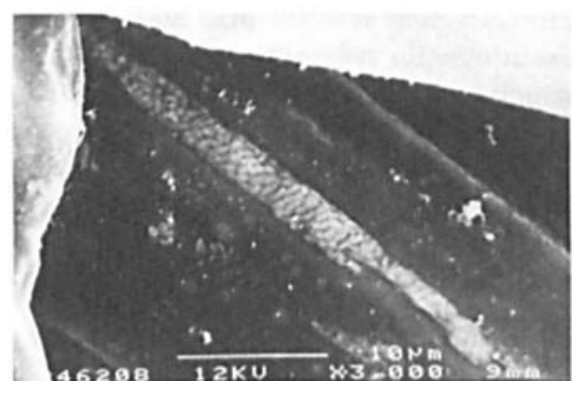

Scanning electron micrograph of a microcolony of Pseudomonas fluorescens strain WCS365 on a tomato root in a mono-axenic system (T. Chin-A-Woeng, W. de Priester and B. J. J. Lugtenberg, unpublished).

Inadequate colonization of the roots by the introduced PGPR strain is considered to be a major reason for suboptimal results, especially for crops with a long cropping period. PGPRs must be metabolically active and present on the roots in sufficiently high numbers at the right time and site to successfully compete with the deleterious organisms or to kill them by antibiosis. For PGPRs that systemically induce resistance, these conditions may require less precision. Root colonization by PGPRs applied to the seed is usually adequate for 4-6 weeks after sowing and therefore sufficient for plant (seedling) establishment. Roots of plants grown in soilless cultures are more easily accessible than those of plants in the open field and PGPRs can be applied to them repeatedly during the cropping period.

Some strains do colonize roots much better than others. A genetic approach can be used to analyse the underlying mechanisms (Lugtenberg et al., 1991). In future the identification of genes for this facility may help in selecting for better strains or in improving strains genetically, for situations where a long lasting protection is required. It also could lead to directed selection or breeding for host genotypes that favour efficient root colonization. New solutions may also be found for exploiting PGPRs that can live inside plants as endophytes, such as $P$. fluorescens strain WCS417, and in particular with respect to induced systemic resistance (Van Peer et al., 1990). Once endophytic, they are less subject to competition with other microorganisms and to environmental influences and possibly more easily distributed to fast-growing root tips and other plant parts.

Plant specificity and influence of soil conditions

Some PGPR strains have a broader crop spectrum in promoting plant growth or suppressing disease than others. For example $P$. fluorescens WCS417 was isolated from wheat grown in a Dutch soil suppressive to take-all disease. When coated on wheat seeds, it suppressed this disease almost as well as $P$. fluorescens strain 2-79 from Washington, in infested fields in the Netherlands. WCS417 also induces systemic resistance in carnation, radish and Arabidopsis thaliana, thereby significantly suppressing fusarium wilt in these crops as well as a foliar disease caused by $P$. syringae in $A$. thaliana. $P$. fluorescens $\mathrm{CHAO}$ was shown significantly to suppress take-all of wheat, black root rot in tobacco and Pythium ultimum in cucumber, thanks to the diversity of antibiotics it can produce.

Plant species or even cultivar and soil conditions, however, may highly influence the effectivity of PGPR strains. As already discussed, iron availability $(\mathrm{pH})$ in the substrate determines the effectiveness of competition for iron and seems also partly to affect the induction of systemic resistance (Leeman et al., 1995a). The biocontrol activity against take-all of wheat of phenazine-producing strains was shown to be negatively correlated with some soil characteristics and positively with others, for example zinc content (see Thomashow and Weller, 
1995). In many cases the host range of PGPR strains is likely to be influenced by crop and soil characteristics, and the use of different locally adapted strains for each disease and each crop may be necessary. Knowledge of the mechanisms and genetics of their rootcolonizing and plant growth-promoting characteristics will facilitate the screening of such strains considerably.

\section{Prospects and limitations}

\section{Prospects}

Now, 15 years after the first reports of plant growth-promoting pseudomonads, our knowledge of the biology of rhizosphere-inhabiting pseudomonads and their interactions has increased impressively. Obviously, scientific understanding in this field will further expand as much still has to be explored. Our present knowledge, however, has already lead to the development of commercially available biological products (biologicals).

If the seed is used as a carrier, the inoculum is positioned where it can most effectively colonize the emerging root and especially control microorganisms (such as Pythium and Rhizoctonia) that cause non-emergence or dampingoff of seedlings. Less obvious effects of seed treatments have been reported on diseases that affect the plant in a later stage. Nevertheless, the biocontrol of Aphanomyces root rot of pea (Parke et

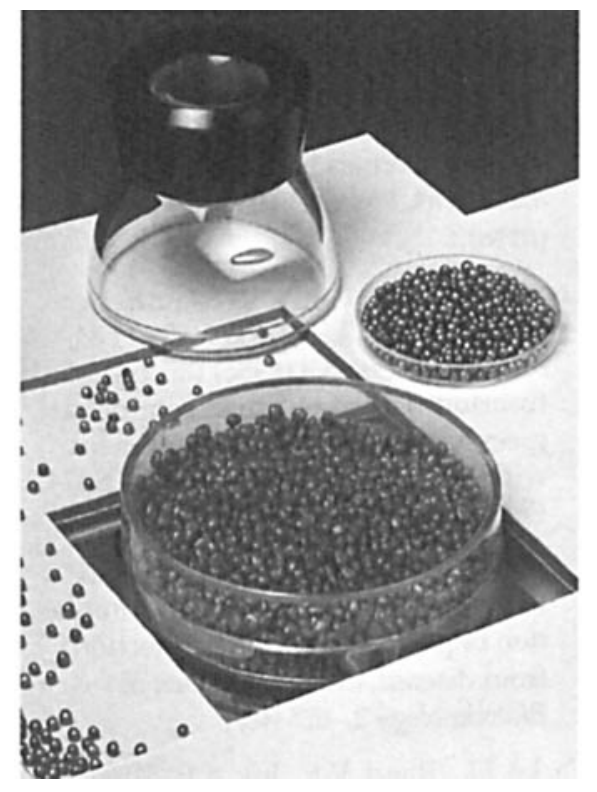

Seeds treated with Biocoat (S \& G Seeds). al., 1991) and take-all in wheat (Thomashow and Weller, 1995) and also our own work with a fluorescent Pseudomonas isolate against Fusarium oxysporum, have repeatedly demonstrated that a seed treatment was more effective than a soil drench.

Recently, more than 10 years of cooperation between the universities of Utrecht and Leiden and S \& G Seeds (Enkhuizen) has resulted in the marketing of 'Biocoat'. Biocoat is a radish seed coating containing $P$. fluorescens WCS374 which significantly contributes to the seedling establishment of radish and can increase yields in commercial greenhouses from 5 to $15 \%$ (Leeman et al., 1995c).

Seed treatments have been attempted in various forms with other bacteria and fungi (Scheffer, 1994); they include commercial or semi-commercial simple dustings such as a Streptomyces griseoviridis strain now marketed as Mycostop, or a Bacillus subtilis strain marketed as Kodiak and Quantum 4000. The biocontrol agent Pythium oligandrum has been experimentally incorporated into seed pellets. Much work has also been done on biocontrol with Trichoderma (Gliocladium) virens as the active ingredient, some of it on seed coatings, but more on soil or substrate applications for which one product, Soilgard, is now on the US market.

There are many ways of improving the performance of biologicals. The technology of seed biocoating offers possibilities of optimizing the survival and functioning of PGPRs that have hardly been explored. Also, combinations of different PGPRs could give a more consistent performance under different environmental conditions and broaden the crop, cultivar and pathogen spectrum (Schippers, 1992;

Alabouvette et al., 1995). This could possibly also be achieved by combining desirable bacterial traits for root colonization, growth promotion or pathogen control in one PGPR strain by genetic modification. However, increased knowledge of the mechanisms involved could also lead to more efficient selection techniques that facilitate the detection and isolation of superior strains from nature.

More attention should also be paid to microorganisms that live as endophytes inside the plant. Van Peer et al. (1990) showed that $P$. fluorescens

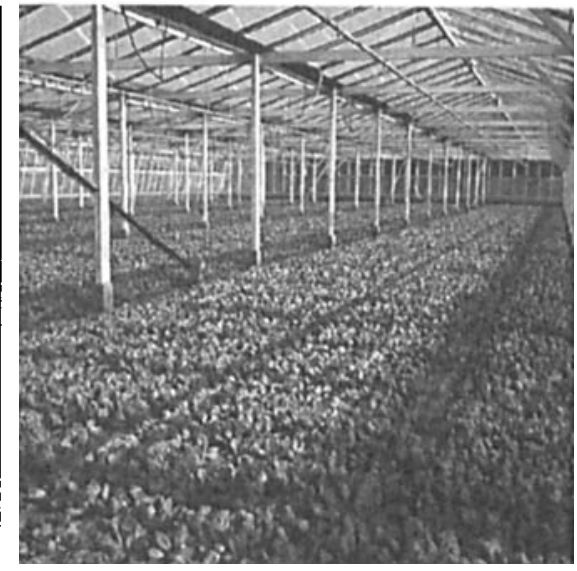

Radishes in the greenhouse ( $S \& G$ Seeds).

strain WCS417, that can induce resistance in a variety of crops including carnation, radish and Arabidopsis, developed as an endophyte in tomato, thereby replacing deleterious endophytic pseudomonads and resulting in promotion of plant growth. Endophytic PGPRs coated on seed may enter the plant tissue soon after seed germination. If so, they may be subject to competition with other microorganisms for only a short period of time and they may therefore induce systemic resistance more efficiently.

\section{Limitations}

The efficacy of biological seed treatments in comparison with alternatives such as genetic resistance of the host or chemical control is a key issue. The outcome of a comparison of the various options will depend on the individual crop parasite combination.

Resistance to a pest or disease in the host plant is attractive because of its often absolute character. Obviously, before resistance breeding becomes an option, sources of resistance have to be available, which is not always the case. The long time frame for a successful breeding programme and therefore the high costs, the specificity of breeding for resistance (only the newly bred varieties carry the desired gene) and the negative correlation with yield are arguments against using genetic resistance (Scheffer, 1994).

Novel seed treatments with fungicides and insecticides are being developed that combine improved efficacy with the use of lower amounts of the active ingredients. Large reductions in the quantities of pesticides can 
be realized by employing such seed treatments. An example of this is the seed treatment developed by S\&G Seeds to control the cabbage root fly (Delia radicum) in cauliflower and Brussels sprouts. Use of seeds coated with chlorpyrifos consistently reduces the use of insecticide by over $95 \%$ and combines efficacy with a very acceptable environmental impact and safe use for the grower.

The examples of biological seed treatments outperforming soil or substrate applications are not rare, but apparently in some cases this is because the amount of inoculum needed cannot be applied as a seed treatment. An example of this may be control of fusarium wilt by a nonpathogenic Fusarium isolate, which was shown to be effective if the antagonist could be applied at a much higher level than the pathogen, for instance in soilless crop cultivation (Alabouvette $e t$ al., 1995). Also, if even very low inoculum densities of a pathogen in the soil cause serious crop losses, the inoculum dose feasible with a seed treatment may be insufficient. This may also be the case with relatively mobile organisms such as nematodes or insect larvae.

The economics of biological seed treatments are currently very complicated. For a company to recover its $R$ \& $D$ costs, a certain generality (in contrast to specificity) will probably be needed; the few current commercial products such as Mycostop and Kodiak indeed have a relatively wide host range. Of course, if a biological seed treatment is specific to the crop, parasite and probably even the environment, the overall environmental impact of the 'biological' will be restricted. However, such a specificity also restricts use of the product to such an extent that it may be impossible for a company to perform the research needed to develop a practical application, especially given the high costs caused by the legislative restrictions on use. Despite the low intrinsic risks in comparison with agrochemicals, government regulations for biologicals are complex, quickly changing and very different from country to country. Clearly, standards on acceptable environmental impacts associated with the introduction of beneficial microorganisms are badly needed.
In the USA, microorganisms intended for biocontrol fall under the federal insecticide, fungicide and rodenticide act (FIFRA) and they must be registered as a 'microbial pesticide' before they can be sold (Cook, 1993). In Europe a diversity of national regulations exists. There are however at least three ways by which microorganisms may be used for pest control without registration. One is if a vector is used to transport the microorganism, the second is if the microorganism establishes itself naturally or if it is enriched because of cultural practices, and the third is if no claim is made for disease control, but the inocula are claimed to "improve plant growth". S \& G followed the latter procedure to market their Biocoat.

It is difficult to understand why a microbial product to control a disease has to be registered as a (microbial) pesticide, especially considering its impact on the biological environment. The localized and temporary changes in soil microbial composition brought about by the introduction of a natural rhizosphere-inhabiting microorganism such as a Pseudomonas strain on seeds are far smaler than those caused by common agricultural practices such as soil steaming, disinfections, fertilization and inundations.

As pointed out by Cook (1993), changes are required in expectation, public confidence and support, unnecessary barriers must be removed and further development of protocols is needed for the efficient discovery of new PGPRs, testing and scaling up. We share his optimistic view that the use of microorganisms to improve plant establishment and growth will progress far beyond the current successes.

\section{References}

Alabouvette, C., Schippers, B., Lemanceau, $P$. and Bakker, P.A.H.M. (1995) Biological control of Fusarium wilts: towards development of commercial products. In: Kuykendall, L.D. and Boland, G.(eds), Plant Microbe Interactions and Biological Control. Marcel Dekker, New York (in press).

Bakker, P.A.H.M., Raaymakers, J.M. and Schippers, B. (1993) Role of iron in the suppression of bacterial plant pathogens by fluorescent pseudomonads. In: Barton, L.L. and Hemming, B.C. (eds) Iron Chelation in Plants and Soil Microorganisms. Academic Press, San Diego, pp. 269-281.

Cook, R.J. (1993) Making greater use of introduced microorganisms for biological control of plant pathogens. Annual Review of Phytopathology 31, 53-80.

Hammerschmidt, R. and Kuć, J. (1995) Induced Resistance to Disease. Kluwer Academic Publishers, Dordrecht.

Hoffland, E., Pieterse, C.M.J., Bik, L. and Van Pelt, J.A. (1995) Induced resistance in radish is not associated with accumulation of pathogenesis-related proteins. Physiological and Molecular Plant Pathology 46, 309-320.

Koster, M., Van Klompenburg, W., Bitter, W., Leong, J., and Weisbeek, P. (1994) Role for the outer membrane ferric siderophore receptor PubB in signal transduction across the bacterial cell envelope. EMBO Journal 13, 28052813.

Leeman, M., Den Ouden, F.M., Van Pelt, J.A., Dirkx, F.P.M., Steijl, H., Bakker, P.A.H.M. and Schippers, B. (1995a) Iron availability affects induction of systemic resistance against fusarium wilt of radish by Pseudomonas fluorescens. Pytopathology 85 (in press).

Leeman, M., Van Pelt, J.A., Den Ouden, F.M., Heinsbroek, M., Bakker, P.A.H.M. and Schippers, B. (1995b) Induction of systemic resistance against fusarium wilt of radish by lipopolysaccharides of Pseudomonas fluorescens. Phytopathology 85 (in press).

Leeman, M., Van Pelt, J.A., Hendrickx, M.J., Scheffer, R.J., Bakker, P.A.H.M. and Schippers, B. (1995c) Biocontrol of fusarium wilt of radish in commercial greenhouse trials by seed treatment with Pseudomonas fluorescens WCS374. Phytopathology 85 (in press).

Lugtenberg, B.J.J., De Weger, L.A. and Bennett, J.W.(1991) Microbial stimulation of plant growth and protection from disease. Current Opinion in Biotechnology 2, 457-467.

Parke, J.L., Rand, R.E., Joy, A.E., King, E.B. (1991) Biological control of Pythium damping-off and 
Aphanomyces root rot of peas by application of Pseudomonas cepacia or P. fluorescens to seed. Plant Disease 75, 987-992

Paulitz, T.C. (1991) Effect of Pseudomonas putida on the stimulation of Pythium ultimum by seed volatiles of pea and soybean. Phytopathology 81, 1282-1287.

Raaymakers, J.M., Van der Sluis, I., Koster, M., Bakker, P.A.H.M., Weisbeek, P.J. and Schippers, B.(1995) Utilization of heterologous siderophores and rhizosphere competence of fluorescent Pseudomonas spp. Canadian Journal of Microbiology 41, 126-135.

Scheffer, R.J. (1994) The seed industry's view on biological seed treatments. In: Seed Treatment: Progress and Prospects. BCPC Monograph No 57, 311-314.

Schippers, B. (1992) Prospects of management of natural suppressiveness to control soilborne pathogens. In: Tjamos, E.C., Papavizas, G.C. and Cook, R.J. (eds),
Biological Control of Plant - Diseases Progress and Challenges for the Future. NATO ASI Series A, Life Sciences, Vol. 230. Plenum Press, New York, pp. 21-34.

Schippers, B., Bakker, A.W. and Bakker, P.A.H.M. (1987) Interactions of deleterious and beneficial rhizosphere microorganisms and the effect of cropping practices. Annual Review of Phytopathology 25, 339-358.

Swaminathan, M.S. (1991 Sustainable agricultural systems and food security. Outlook on Agriculture 20, 243-249.

Thomashow, L.S. and Weller, D.M. (1995) Current concepts in the use of introduced bacteria for biological control: mechanisms and antifungal metabolites. In: Stacey, G. and Keen, N.(eds), Plant-Microbe Interactions Vol. 1, Chapman and Hall, New York, pp. 187-235.

(C) CAB INTERNATIONAL. 1995
Van Peer, R., Punte, H.L.M., De Weger, L.A. and Schippers, B. (1990) Characterization of root surface and endorhizosphere pseudomonads in relation to their colonization of roots. Applied and Environmental Microbiology 56, 2462-2470.

Van Peer, R., Niemann, G.N. and Schippers, B. (1991) Induced resistance and phytoalexin accumulation in biological control of fusarium wilt in carnation by Pseudomonas sp. strain WCS417r. Phytopathology 81, 728-734.

Voisard, C., Bull, C.T., Keel, C., Laville, J., Maurhofer, M., Schnider, U. Défago, G. and Haas, D. (1994) Biocontrol of root diseases by Pseudomonas fluorescens CHAO: current concepts and experimental approaches. In: O'Gara, F, Dowling, D.N. and Boesten, B. (eds), Molecular Ecology of Rhizosphere Microorganisms: Biotechnology and the Release of GMO's. VCH, Weinheim, pp. 67-89. 